\title{
Ensuring energy efficiency and ways to develop energy security
}

\author{
Alexey Efimiev ${ }^{1}$, Olga Kutsygina ${ }^{1}$, Margarita Agafonova ${ }^{1, *}$, and Andrei Chugunov ${ }^{1}$ \\ ${ }^{1}$ Voronezh State Technical University, Moscovskiy prospect, 14, Voronezh, 394026, Russia
}

\begin{abstract}
The paper assesses the relevant problems of the global energy paradigm, with emphasis on ensuring energy security. To solve this problem, the state and prospects of world energy markets and the forecast for their development are analyzed. The paper substantiates the importance of improving energy efficiency in Russia. It also analyzes and displays the most important aspects of global energy problems, highlights the dynamics of the global balance of energy consumption, analyzes the development of renewable energy sources. The study determined the place of fuel and energy sector in the global economy. Forecasts of global electricity consumption are presented. The paper focuses on the need for measures that contribute to overcoming energy threats in the global energy market.
\end{abstract}

\section{Introduction}

Energy issues are topical issues of the modern global nature. Nowadays, there are several scenarios for the development of global energy. In this paper, based on statistical data, forecasts of global electricity consumption are presented. It also focuses on the need for measures that contribute to overcoming energy threats in the global energy market.

The global energy (energy source) problem is the problem of providing the constantly growing world population with fuel and energy.

Forecasting the development of global energy in the long term is a task that has been faced by researchers and scientists for many years. But at the moment, a number of new problems and circumstances that have appeared recently have made this problem especially urgent.

The most effective and economically feasible is an intensive way to solve the energy problem, which means to expand production by unit of energy consumption. For the successful development of the global economy in the long term, it is necessary to increase the efficiency of electricity consumption and use all environmentally friendly and economical energy sources.

Nowadays, during global changes and shifts, our country needs to implement a number of priority tasks:

$\checkmark$ ensuring stable economic growth;

$\checkmark$ ensuring energy security;

\footnotetext{
"Corresponding author: agaf-econ@yandex.ru
} 
$\checkmark$ maximum reduction and control of greenhouse gas emissions - in the environmental sphere.

The latter aspect will serve to significantly reduce the degree of pollution of the air envelope of our planet and lead to positive shifts in the state of the environment.

Backward infrastructure in the field of district heating and electric power requires urgent investment. Using the following measures, investments can be attracted to improve and increase energy efficiency:

$\checkmark$ development of sources of regenerative energy

$\checkmark$ formation of the most profitable oil and gas reserves

$\checkmark$ fundamental changes in export policy

$\checkmark$ reducing the dependence of the fuel and energy sector on equipment imports;

$\checkmark$ development of renewable energy sources (RES);

$\checkmark$ development of the most profitable oil and gas reserves and a changes in export strategies

The purpose of the energy policy of Russia is the most efficient use of natural energy resources and the potential of the energy sector for sustainable economic growth, improving the quality of life of the country's population and strengthening its foreign economic position.

Energy security is one of the most important components of a country's national security. Energy security - the state of security of a country, society, state and national economy from threats (determined by external (geopolitical, macroeconomic, market) factors, as well as the state and functioning of the country's energy sector) and stable energy supply. Ensuring energy security is determined by resource sufficiency, economic affordability, environmental and technological affordability.

Over the years of the implementation of the Energy Strategy of Russia for the period until 2020, the energy security of Russia was fully ensured. At the same time, it was not possible to avoid local short-term violations of the energy security of certain regions, which became a reflection of the existing systemic problems in the Russian energy sector.

The world economy is going through a very difficult period, which has the most direct impact on the state of the energy sector. The struggle for access to energy has become critical. The states strive to provide themselves with reliable energy resources both by establishing control over traditional energy resources (including using measures of political and economic pressure) and by introducing advanced technologies for the development and processing of traditional hydrocarbon resources, as well as the industrial use of renewable energy sources.

In this situation, the creation of a global energy system becomes one of the most important priorities for sustainable development, since energy provides a solution to a number of global problems of mankind and prevents their occurrence. Nowadays, about 1.2 billion people (17\% of the world population), mainly in the countries of the Asia-Pacific region and Central Africa, continue to live without electricity.

\section{Materials and Methods}

A long-term state energy policy is carried out on the following unchanging principles:

- the sequence of actions of the state to implement the most important strategic guidelines for the development of energy;

- interest in creating strong and sustainable energy companies that adequately represent

Russia in foreign markets;

- the validity and predictability of state regulation.

The main strategic benchmarks for long-term state energy policy are: 
energy security, energy efficiency of the economy, budgetary energy efficiency, environmental safety of energy.

The main components of state energy policy include:

subsoil use and management of the state subsoil fund, development of domestic energy markets, formation of a rational fuel and energy balance,

regional energy policy, innovative, scientific and technical policy in the energy sector.

It is proposed to implement the state energy policy in 3 stages.

The first stage is the stage of overcoming the crisis and forming the foundations of a new economy. The main task is to overcome the crisis in the economy and energy in order to achieve a sustainable pace of economic and energy development, provided for by the Concept.

The second stage is the stage of transition to innovative development and the formation of infrastructure of the new economy. The dominant feature of the second stage will be a general increase in energy efficiency in the fuel and energy sectors and the economy as a whole.

The third stage is the stage of development of an innovative economy. The main content of this stage will be a gradual transition to the energy of the future with fundamentally different technological possibilities for further development, relying on the highly efficient use of traditional energy resources and new non-hydrocarbon energy sources and technologies for its production.

Domestic demand for energy is determined by the expected dynamics of economic development, changes in the structure of the economy and the level of its specific energy intensity.

Reducing the specific energy intensity of the economy is the central task of the energy policy of Russia, without which the energy sector will inevitably restrain the country's socio-economic development.

Russia occupies one of the leading places in the global energy turnover system, and is actively involved in world trade and in international cooperation in this area.

\section{Country's position in the global hydrocarbon market}

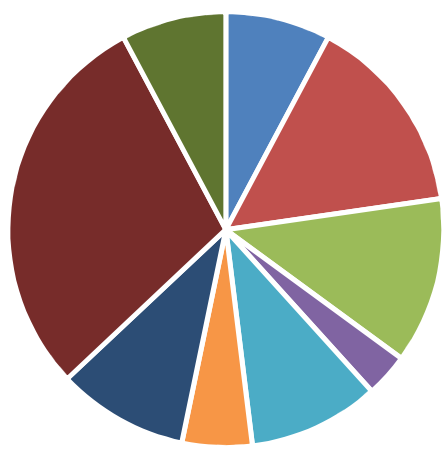

- Crude oil production

- natural gas reserves

- Coal reserves

- Nuclear power

- reactor building

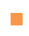

- Spent fuel conversion

- Uranium enrichment

natural uranium mining

- Steam coal trading

Fig. 1. The country's position in the global hydrocarbon market. 
In recent years, Russia has been a leader in terms of crude oil production and provides $12 \%$ of the world oil trade - this is $4 / 5$ of the volume of Russian oil exported to Europe (Russia's share is 30 percent). Russia ranks first in the world in terms of natural gas reserves ( $23 \%$ of world reserves); $25 \%$ of the global natural gas trade, dominating both the European gas market and the CIS market.

Having a unique gas transmission system, Russia plays an important role in ensuring gas supplies to Europe and the CIS countries. Russia holds 2nd place in the world in terms of coal reserves (19\% of world reserves), 5th place in terms of annual production ( $5 \%$ of world production) and provides about $12 \%$ of world trade in thermal coal.

Russian nuclear energy accounts for $5 \%$ of the global nuclear power generation market. Features of the upcoming period of development of global energy markets are associated with the processes of their restructuring, an increase in the share of developing countries, and increased competition. At the same time, the degree of uncertainty and risks in the development of global markets has significantly increased recently.

In the future, Russia will retain its position in the global energy market as the largest energy carrier, but it will also qualitatively change the nature of its presence there by diversifying the product structure and directions of Russian energy exports, actively developing new forms of international energy business and expanding the presence of Russian companies abroad. This will reduce the risk of mono-dependence of the Russian energy sector on energy exports to Europe, as well as increase the profitability and effectiveness of international activities of Russian energy companies without a significant increase in exports of primary energy sources.

\section{Results}

The tendency of many countries to reduce the share of hydrocarbons in the global energy balance is causing significant changes in the global energy market. In these conditions, Russia, which is one of the largest exporters of traditional energy resources, is faced with the problem of the need for a transition to innovative resource development of the economy.

Leading specialized organizations present forecasts and scenarios for the development of global energy on the basis of quantitative and qualitative analysis of indicators of the development of the energy system [1]. According to expectations, the global demand for energy will increase by about $50 \%$, for electricity - almost twice.

As for global oil demand, according to the calculations of the International Energy Agency (IEA) « World Energy Outlook 2019 », it will increase by 6.6 million b/s and will be 103.5 million $\mathrm{b} / \mathrm{s}$.

According to the analysis of BP British Petroleum Corporation, gas will overtake coal in terms of its share in primary energy and will become one of the largest sources of energy by 2035 .

Changes in the share of primary energy consumption, especially in underdeveloped countries, can be traced in all possible scenarios.

If we talk about nuclear energy, its position and development prospects raise many doubts and are uncertain. Nuclear energy can follow an inertial, stagnant or innovative scenario. The inertial scenario involves the development and increase of industrial energy in developing countries. It results in the growing demand for energy and the aggravation of the global environmental problem. The stagnation scenario is based on the search and application of political, legal and economic measures to combat the consequences and risks of the inertial scenario. The innovative scenario is the formation of a new type of energy. This process will help reduce environmental risks and the emergence of new technological 
opportunities for consumers. However, the most expected is the middle scenario, since extremes such as rapid growth or complete closing up can lead to disastrous consequences.

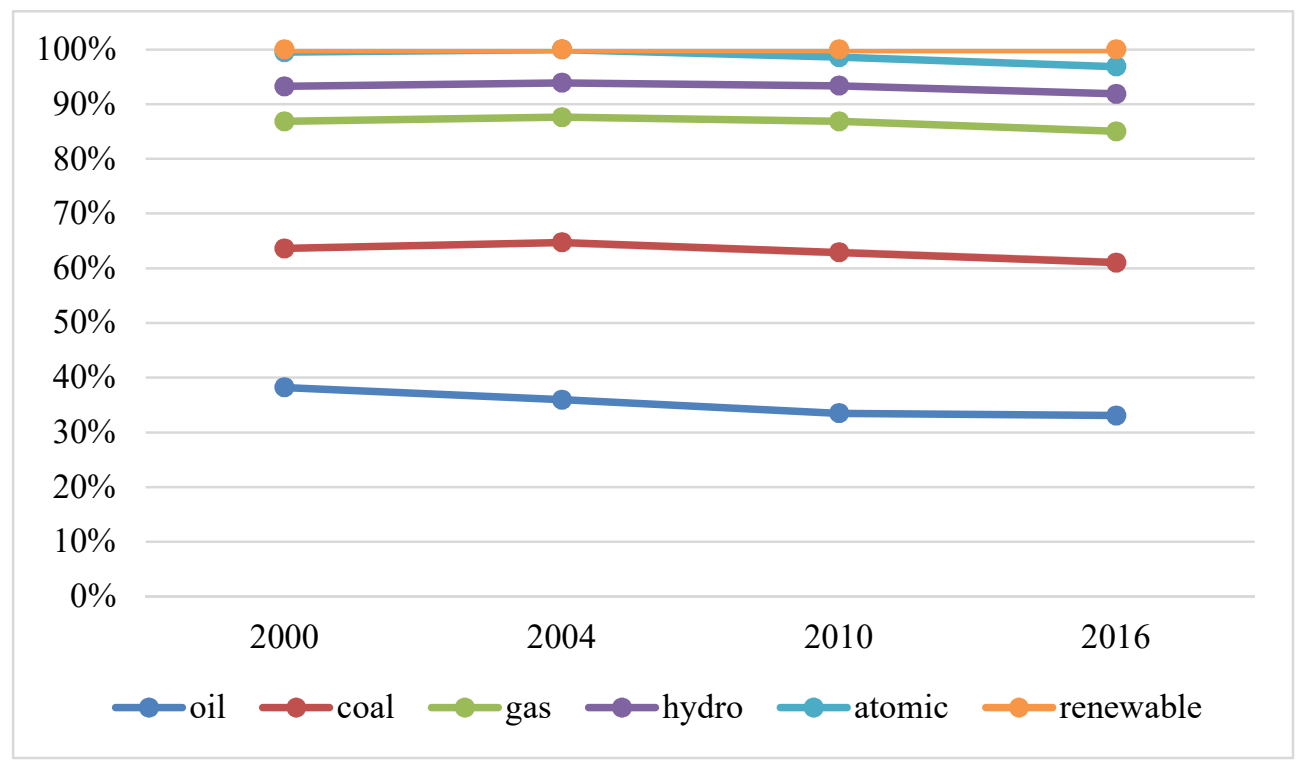

Fig. 2. Changes in the global balance of electricity consumption.

\subsection{Changes in the global balance of electricity consumption}

The World Energy Council (WEC) is one of the largest non-governmental organizations in the global energy market. As one of the ways to solve this problem, WEC proposed the concept of "energy trilemma ", which is based on finding a balance point between the desire for energy security, affordability of energy supply and environmental sustainability $[2]$.

The vast majority of the growth in global electricity consumption is observed in the Asian region (about 80\%). Due to economic growth, the aggregate demand for electricity has increased in China, and now a significant part of energy consumption in Asia falls on it.

In the United States, electrical energy consumption has not fluctuated significantly. In 2017 , it fell by $1.2 \%$. In 2018 , it recovered and amounted to $3.2 \%$. The residential sector (a $6.3 \%$ increase) made a significant contribution to this increase due to an increase in energy consumption for household appliances (which is approximately $1 / 2$ of electricity consumption) and air conditioning (almost every American has air conditioning in his house). In some countries (Canada, Brazil), economic growth has affected electricity consumption. Demand for electricity is growing rapidly in developing countries such as Egypt or Iran.

By analogy with 2017, electricity consumption in European countries in 2018 did not undergo significant changes: it decreased in Germany and France, in the UK, Italy, Spain it stabilized, and in the Netherlands, Turkey and Poland - it increased significantly. 


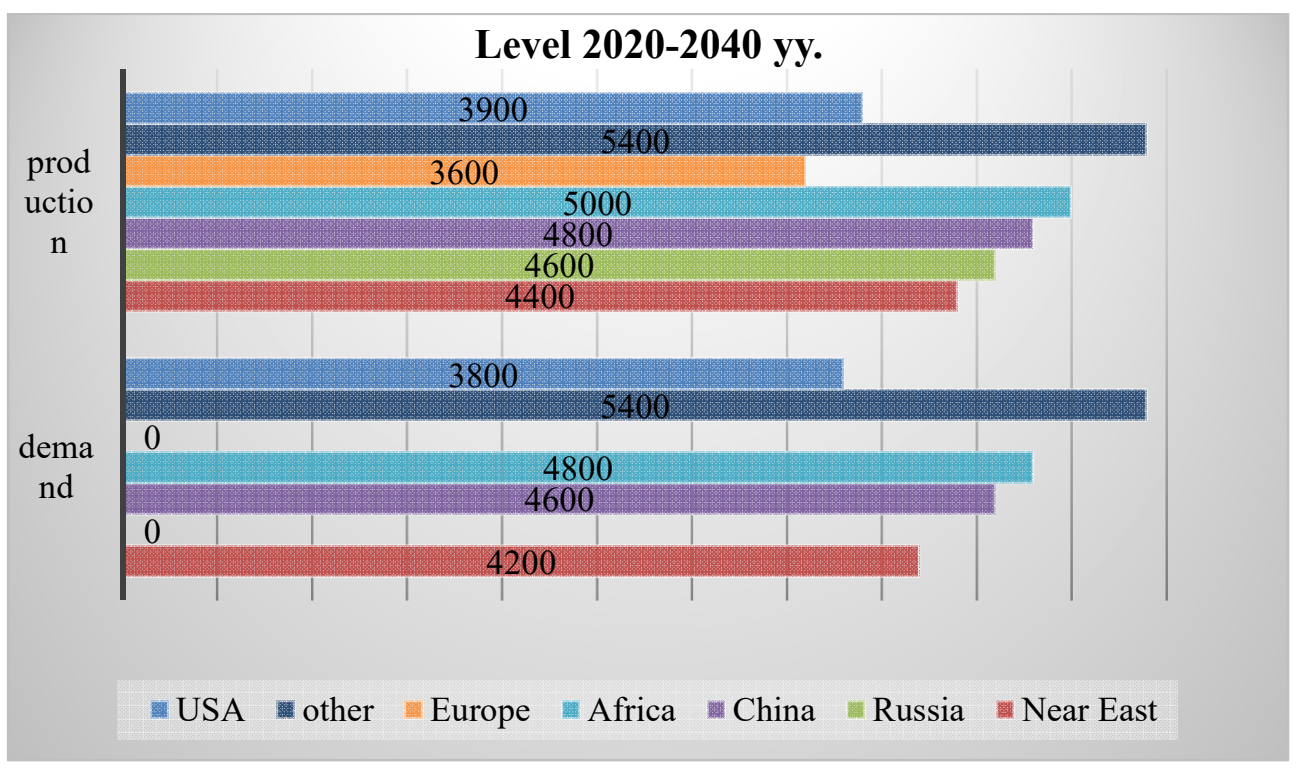

Fig. 3. Levels of production and consumption (demand) of natural gas in various regions of the world in the evolutionary scenario (according to BP Energy Outlook 2019).

\subsection{Analysis of the development and consumption of renewable energy sources}

It is worth mentioning the analysis of the development of consumption of primary energy resources.

In the recent past, renewable energy has received financial support from the government in many countries. This has contributed to the development of renewable energy. As the situation of primary energy resources improves, state support will decline and move to institutional regulation through the rules of the energy system.

In developed countries, only renewable energy sources and gas will be used as energy carriers in 2017 - 2040. In countries that are not part of the Organization for Economic Cooperation and Development, in addition to renewable sources and gas, coal and other energy sources will be used.

At the present stage of its development, the energy sector provides $9 \%$ of the final energy consumption for heating and cooling due to bioenergy, to a much lesser extent from solar thermal energy. About $3 / 4$ of the heat consumption worldwide is currently provided by fossil fuels. Although the total capacity and heat generation from RES continues to grow steadily. In 2015, the growth slowed down due to a drop in oil prices. At the same time, in the European Region, solar energy was involved in district heating systems [3]. Despite the growing interest in district heating systems, renewable energy sources are rarely used in it.

China is at the forefront of most renewable energy sectors, and is also holding promising events and programs to develop and improve them. However, Russia annually produces 8.6 billion $\mathrm{kW}$ of electricity using renewable energy sources. This indicator is not more than $1 \%$ of the total electric energy production. Despite the fact that the Russian Federation is a country rich in hydrocarbon raw materials, it is possible to actively take measures to develop renewable energy in the northern regions (where wind energy can be successfully developed) and the southern regions (favorable for the development of solar energy). 
One of the conditions for sustainable development of the world is ensuring free access to economical, safe and modern energy services, which will be based on renewable energy sources. Many countries are now striving to achieve this goal.

\subsection{The place of the fuel and energy sector in the international economy}

Steady long-term growth of global demand for primary electricity is currently forecasted, especially in developing countries [4].

China, Russia, countries of the Near and Middle East, Australia - countries that provide more than $60 \%$ of the world's energy production. The least endowed with energy resources are the countries of the Asia - Pacific region. The rapid growth in energy consumption against the background of a much slower growth in supply has been affecting prices for all types of energy resources for several years, provoking their growth. The current situation is a threat to both the global economy and the economy of individual countries [5]. As for Europe, focusing on the growth in demand for primary energy resources within the region, the interest of European countries in the Russian Federation, which is one of the largest suppliers of these resources, will continue in the next decade.

The development of international energy trade requires adequate infrastructure development. However, in recent years, there has been a number of difficulties:

- construction of longer and more expensive pipelines is required. This is due to the territorial remoteness of new extractive regions from the main sales markets;

- some transportation routes are already reaching their full capacity;

- construction of oil refineries and terminals for regasification of liquefied natural gas (LNG) in developed countries causes indignation of the local population;

- the jump in steel and energy prices creates problems associated with attracting financial resources.

\section{Discussions}

The main problem in this area is the significant unrealized potential of organizational and technological energy conservation, which is up to 40 percent of the total domestic energy consumption. According to existing estimates, the proportion of various components in the total value of the indicated potential is characterized by the following data:

-residential buildings - 18-19 percent;

-electric power, industry, transport - in the range from 13 to 15 percent in each case;

-heat supply, services, construction - in the range from 9 to 10 percent in each case;

-fuel production, flaring of associated gas, energy supply of state institutions - in the range from 5 to 6 percent in each case;

-agriculture - 3 to 4 percent.

To achieve the energy efficiency of the economy, the following measures of state energy policy will be used, grouped by the applicable mechanisms for its implementation:

-creation of a favorable economic environment [6];

-formation of a system of promising regulations, standards and norms;

-support for strategic initiatives;

-stimulating the development and use of new energy technologies that create products with qualitatively new consumer properties;

-realization of a complex of information and educational programs (events), promotion of energy conservation;

-development and support of international cooperation in the field of energy conservation and energy efficiency, studies in search of new energy sources. 


\section{Conclusion}

This paper presented forecasts and scenarios of the development of global energy:

expectations regarding changes in demand for energy and electricity, oil, gas and coal were showed;

changes in the share of primary energy consumption were tracked, and prospects for the development of nuclear energy were studied.

The change in the global balance of electricity consumption was also studied:

from the data presented, it can be concluded that in countries with steady economic growth, demand for electricity is increasing (especially in the USA, China). But this pattern is not traced in relation to nuclear and hydropower.

An analysis of the development of primary energy consumption in the energy sector was made:

analysis of the current situation of renewable energy sources shows that the governments of many countries are aware of the need to support renewable energy sources and stimulate their development in every way. However, so far, most widely renewable sources of energy have found their application in developed countries.

Among other things, the paper determined the place of the fuel and energy sector in the international economy:

nowadays, an increase in energy demand is expected, which will have a direct impact on the prices of fuel and energy resources, which undoubtedly poses a threat to the global economy.

The paper considers the nature and direction of this relationship, taking into account the heterogeneity of economic systems in various regions of the world and the influence of the global crisis factor.

The authors show that structural shifts in the global economy, new trends in improving energy efficiency, energy supply and prices make it necessary to regularly reassess the relationship between economic growth and energy consumption.

The implementation of the main provisions of the state energy policy and the specification of the parameters of the most important measures for the development of energy will lead to the identification of the most important benchmarks and the concentration of the main available resources to achieve these benchmarks. Following these principles will allow verifying the actual results of the fuel and energy sector with the targets of the state's long-term strategy, and also adjusting the current benchmarks of the state energy policy while maintaining its main focus. This should be one of the most important mechanisms to reduce the risks of implementing the state energy strategy. In this case, the following will be provided:

1. Guaranteed energy security of Russia and its regions;

2. Russia's full participation in the formation of the global energy security system, including through diversification of export supplies;

3. Reducing the dependence of the country's economic welfare on the oil and gas sector with a decrease in the share of the fuel and energy complex in the structure of gross domestic product from 30 to $18 \%$;

4. Reduction in the specific energy intensity of the gross domestic product by at least 2.3 times;

5. The growth of financial and economic stability and budgetary efficiency of economic entities of the fuel and energy sector.

The energy problem has been and remains an acute global problem. However, mankind is gradually shifting from energy based on limited organic resources to energy on an almost inexhaustible basis (nuclear energy, Earth's heat, etc.). In this period, development and innovation in the field of energy-saving technologies and global energy saving play a large 
role. In the long run, the solution to the energy problem will depend on the degree of reduction in the energy intensity of the economy.

\section{References}

1. M.S. Agafonova, Uspekhi sovremennogo estestvoznaniya 1, 101 (2012)

2. J. Jewell, V. Vinichenko, N. Bauer, E. Cian, Climatic Change 136, 83-94 (2016)

3. M.S. Agafonova, I.S. Ivanova, Sovremennye naukoemkie tekhnologii 10-1, 134-135 2013

4. A.S. Ovsyannikov, V.A. Bolgov, A.V. Vorotyntseva, A.S. Efimiev, International Scientific Conference Energy Management of Municipal Facilities and Sustainable Energy Technologies EMMFT 2018, 695-703 (2018)

5. A.S. Efim'ev, I.A. Provotorov, A.V. Vorotynceva., H.F.M. El'shammari, Finansovaya ekonomika 8, 353-355 (2019)

6. M.S.Agafonova, Nauchnoe obozrenie 13, 276-278 (2015)

7. K.E. Kovalenko, S.Y. Bakhvalov, A.O. Zekiy, V.V. Vikulina, S.A. Tinkov, T.V. Tkacheva, Journal of Entrepreneurship Education 22(3), 1-7 (2019)

8. E. Nezhnikova, S. Santos, E. Egorycheva, Advances in Intelligent Systems and Computing AISC 983 DOI: 10.1007/978-3-030-19868-8_12

9. S.A. Tinkov, E.V. Tinkova, Smart Innovation, Systems and Technologies, Springer 139 (2019) 